\title{
Significance of Serum Uric Acid in Patients with Chronic Respiratory Failure Treated with Non-invasive Positive Pressure Ventilation
}

\author{
Toru Kadowaki ${ }^{1}$, Hironobu Hamada ${ }^{1}$, Akihito Yokoyama ${ }^{2}$, Masahiro Abe ${ }^{3}$, \\ Kazutaka Nishimura ${ }^{3}$, Nobuoki Kohno ${ }^{2}$, Junya Inata ${ }^{4}$, Toshihiko Kuraoka ${ }^{4}$, \\ Chie Moritani ${ }^{5}$ and Jitsuo Higaki ${ }^{1}$
}

\begin{abstract}
Purpose The aim of the study was to evaluate serum uric acid (UA) levels before and after non-invasive positive pressure ventilation (NPPV) to assess the utility of serum UA as an indicator of acute exacerbation of chronic respiratory failure (CRF) in patients treated with NPPV.

Methods We analyzed change in the serum UA level in 29 patients with CRF due to restrictive thoracic disease and treated with NPPV.

Results After NPPV therapy, $\mathrm{PaO}_{2}$ was significantly increased and $\mathrm{PaCO}_{2}$ was significantly decreased in all patients. Sixty-two percent of patients (18 of 29) showed a decreased serum UA/creatinine $(\mathrm{Cr})$ ratio after NPPV therapy, but, overall, there was no significant change in serum UA/Cr $(P=0.0688)$. The change in serum UA/Cr was not correlated with the changes in $\mathrm{PaO}_{2}$ and $\mathrm{PaCO}_{2}$ after NPPV. When we compared patients in whom serum UA/Cr decreased $(n=18)$ with patients in whom serum UA/Cr did not decrease $(n=11)$, there were significantly fewer patients who suffered CRF exacerbation in the group with a decrease $(P=0.0021)$. Furthermore, the cumulative proportion (Kaplan-Meier) of patients who did not suffer exacerbation of CRF was significantly higher in the group in which serum UA/Cr decreased $(P=0.0003)$.

Conclusions Our data suggest that serum UA may be a useful clinical indicator of CRF exacerbation in patients treated by NPPV.
\end{abstract}

Key words: serum uric acid, chronic respiratory failure, non-invasive positive pressure ventilation, exacerbation

(DOI: 10.2169/internalmedicine.46.6120)

\section{Introduction}

Continuous nocturnal oxygen desaturation due to sleepassociated hypoventilation results in daytime hypoxemia and hypercapnia in patients with chronic respiratory failure (CRF) (1). A possible sequela of sleep-associated hypoxemia is tissue hypoxia (2). Hypoxic conditions trigger a purine degradation cascade (3-5). Increased plasma levels and ex- cretion of purine metabolites have also been observed in exercising human subjects (6) and in critically ill patients (7) under conditions of hypoxia and ischemia. Serum adenosine, a purine metabolite, may be a more sensitive marker of tissue hypoxia than uric acid (UA). However, the measurement of adenosine is technically difficult because of its short halflife in plasma (8). Consequently, UA is widely used as a clinical marker of tissue hypoxia because it is not metabolized further, and it is easy to sample and inexpensive to as-

\footnotetext{
${ }^{1}$ Department of Integrated Medicine and Informatics, Ehime University Graduate School of Medicine, Ehime, ${ }^{2}$ Department of Molecular and Internal Medicine, Graduate School of Biomedical Sciences, Hiroshima University, Hiroshima, ${ }^{3}$ Department of Respiratory Medicine, Ehime National Hospital, Toon, ${ }^{4}$ Department of Internal Medicine, Federation of National Public Service Personnel Mutual Aid Association, Yoshijima Hospital, Hiroshima and ${ }^{5}$ Department of Internal Medicine, Asa Citizen's Hospital, Hiroshima

Received for publication July 11, 2006; Accepted for publication December 27, 2006

Correspondence to Dr. Hironobu Hamada, hhamada@m.ehime-u.ac.jp
} 
sess (9).

Serum and urinary UA are reported to be useful markers reflecting hypoxia in patients with various diseases such as obstructive sleep apnea syndrome (OSAS) (2, 8-11), chronic obstructive pulmonary disease (COPD) $(9,12,13)$, chronic heart failure $(14,15)$, primary pulmonary hypertension $(16)$, cyanotic congenital heart disease (17), and Eisenmenger syndrome (18). The therapeutic effects of oxygen and nasal continuous positive airway pressure (nCPAP) on UA excretion in hypoxemic patients have been examined. Oxygen therapy markedly reduced excretion of urinary UA in COPD patients (12). Additionally, several studies showed that overnight use of nCPAP reduced the urinary UA/creatinine ratio (UA/Cr) in OSAS patients (8-11).

Efficacy of long-term non-invasive positive pressure ventilation (NPPV) in patients with CRF has been reported (19). In general, NPPV acts by relieving respiratory muscle fatigue, improving respiratory system compliance by reversing microatelectasis of the lung, and lowering the respiratory center "set point" for $\mathrm{CO}_{2}$ by ameliorating chronic hypoventilation (19). Chronic NPPV is effective for ventilatory failure due to restrictive thoracic disease (RTD) such as pulmonary tuberculosis sequelae (PTS), kyphoscoliosis (KS), or neuromuscular disease $(19,20)$. NPPV is widely used for patients with hypercapnic hypoxemic respiratory insufficiency. However, little is known about the effect of NPPV on tissue hypoxia and the clinical importance of serum UA in patients with CRF receiving NPPV. We hypothesized that long-term NPPV in patients with CRF would improve hypoventilation and tissue hypoxia, leading to a decrease in serum UA.

We conducted a preliminary study comparing serum UA levels before and after NPPV therapy to assess the utility of serum UA as an indicator of acute exacerbation of CRF in patients treated with NPPV.

\section{Patients and Methods}

\section{Study subjects}

Data were collected from patients with CRF due to RTD (PTS or KS) who were prescribed chronic NPPV therapy at one of our institutions during the 6-year period 1999-2005. The clinical data of 29 patients were retrospectively analyzed. All 29 patients met the criteria for hypercapnic respiratory failure $\left(\mathrm{PaCO}_{2} \geq 45 \mathrm{mmHg}\right.$ in room air) (21). PTS was defined as severe restrictive pulmonary dysfunction with or without cor pulmonale due to previous M. tuberculosis infection involving the chest wall and lung parenchyma and/ or pleura (22). KS was defined as a Cobb angle of $>50^{\circ}$ (23).

All patients met the selection guidelines for long-term non-invasive ventilation for RTD, as previously reported (19). In brief, all patients showed typical symptoms such as morning headaches, daytime hypersomnolence, energy loss, and impaired gas exchange attributable to chronic daytime and sustained nocturnal hypoventilation (19). Before NPPV therapy, all study patients were in clinically stable condition (no exacerbation of the CRF or hospital admission for at least 1 month prior to the study). No patient had rapidly progressive neuromuscular disease or obesityhypoventilation syndrome. There was no evidence of renal dysfunction in any patient. Venous and arterial blood sampling was performed just before the start of NPPV therapy, and the resulting laboratory values were recorded as beforeNPPV values. Venous and arterial blood samples were obtained again at least 10 months after NPPV, and resulting values were recorded as after-NPPV values.

\section{Blood sampling for UA measurement and arterial blood gas (ABG) analysis}

For measurement of serum UA and $\mathrm{Cr}$, venous blood was obtained after an overnight fast. Serum UA and $\mathrm{Cr}$ levels were determined by the uricase-peroxidase method and creatinase-peroxydase method, respectively (24). Arterial blood samples were obtained from the brachial or femoral artery with patients in a supine position breathing room air or receiving supplemental oxygen. Arterial blood samples were obtained after NPPV therapy under these same conditions. The UA/Cr was calculated to adjust for kidney function, as previously reported $(8-11,25)$.

\section{Measurement of change in serum UA ( $\triangle U A / C r)$}

$\Delta \mathrm{UA} / \mathrm{Cr}$ was calculated as described previously (2): $\Delta \mathrm{UA} /$ $\mathrm{Cr}=100 \% \times(\mathrm{UA} / \mathrm{Cr}$ after NPPV therapy-UA/Cr before NPPV therapy) $\div \mathrm{UA} / \mathrm{Cr}$ before NPPV therapy.

\section{NPPV}

Bilevel NPPV was delivered via nasal or full face mask with a NIP nasal A (Teijin Pharma Limited, Tokyo, Japan) or CLEAN AIR EZ (Fukuda Denshi Co., Ltd., Tokyo, Japan) or BiPAP S/T (Fuji Respironics, Co., Ltd., Tokyo) ventilator. The commercial masks were of appropriate size to fit to each patient's nose or face. In 27 cases, the ventilator was set to spontaneous/timed mode at the maximal tolerated inspiratory positive airway pressure and at an expiratory positive airway pressure in the range of 3-6 $\mathrm{cm} \mathrm{H}_{2} \mathrm{O}$, with a back-up respiratory rate below the awake spontaneous breathing rate. The ventilator was set to timed mode in the other two cases. Oxygen was supplied from the mask side port at a flow rate needed to achieve a target $\mathrm{SpO}_{2} \geq 90 \%$.

\section{Exacerbation of CRF}

Exacerbation of CRF was defined as an event in the natural course of the disease characterized by a change in the patient's baseline dyspnea, cough and/or sputum to warrant a change in management (26) with uncompensated respiratory acidosis $(\mathrm{pH}<7.30)(27)$.

\section{Comparison of patients with and without a decrease in serum UA}

Patients were classified into two groups according to 
Table 1. Baseline Characteristics of Study Patients $(n=29)$

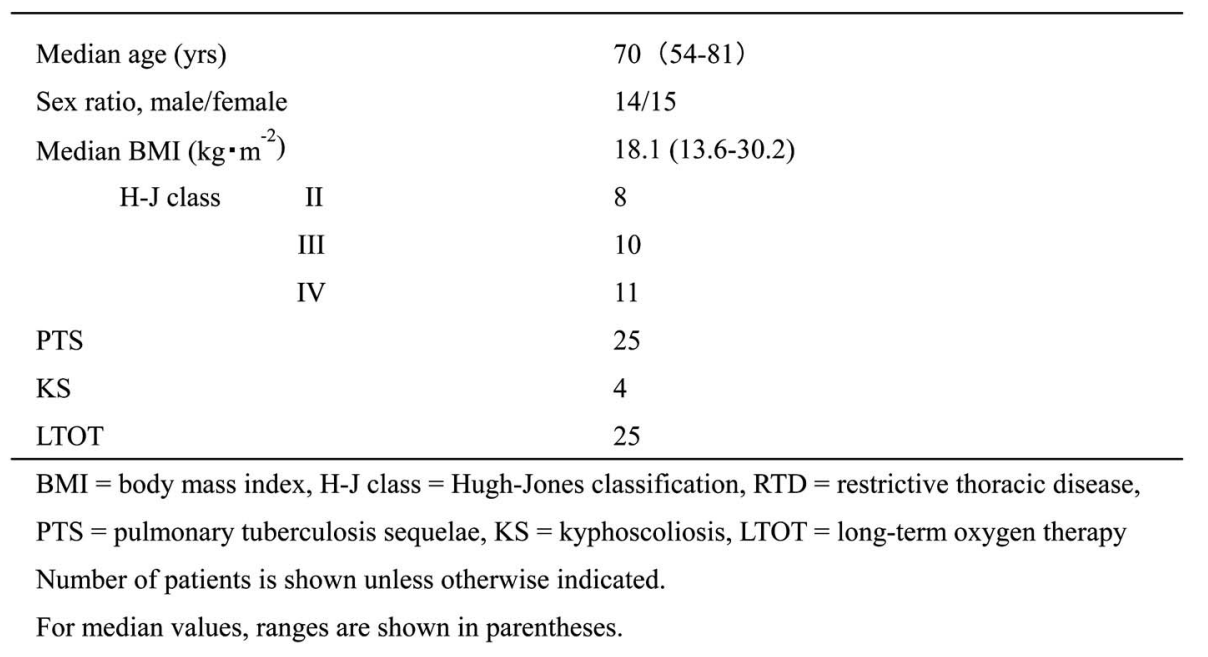

whether serum UA/Cr decreased after NPPV therapy: a UA/ $\mathrm{Cr}$ decrease group and a non-UA/Cr decrease group.

\section{Statistical analysis}

Data are expressed as median values with ranges shown in parentheses. Differences between ABG values before and after NPPV therapy and between laboratory values before and after NPPV therapy were analyzed by Wilcoxon signedrank test. Differences in baseline characteristics, in changes in $\mathrm{ABG}$ values, and in the number of CRF exacerbations between the UA/Cr decrease group and the non-UA/Cr decrease group were analyzed by Mann-Whitney $U$ test. Spearman's rank correlation coefficient was used to examine correlation between variables. Differences between groups in the number of patients taking diuretics and in the number who suffered CRF exacerbation were analyzed by Fisher's exact test. The proportion of patients who did not suffer exacerbation of CRF in each of the two groups was derived by the Kaplan-Meier method and was compared by log-rank test. Statistical significance was accepted at $P<0.05$.

Results

Baseline characteristics of the study patients are shown in Table 1. Median age of the patients (14 men and 15 women) was 70 years (range, 54-81 years). Twenty-five patients had PTS, and 4 had KS. Patients were classified into three groups according to the degree of clinical breathlessness per Fletcher-Hugh-Jones classification (28): grade 2, $\mathrm{n}=8$; grade $3, \mathrm{n}=10$, and grade $4, \mathrm{n}=11$. No patient was taking any medication such as alloprinol, a thiazide diuretic, or aspirin during the study, but $52 \%$ of patients (15 of 29) were taking a loop diuretic, and 24\% (7 of 29) were taking theophylline. Body mass index was $18.1(13.6-30.2) \mathrm{kg} / \mathrm{m}^{2}$. Eighty-six percent of patients (25 of 29) had received long-term oxygen therapy (LTOT) before NPPV therapy. Indices of lung function obtained before the study were as follows: vital capacity (VC) $1.00(0.47-2.11) \mathrm{L}$ (percentage of predicted value 38.1 (21.6-58.6)), $\mathrm{FEV}_{1.0} 0.59$ (0.34-1.13) L, and $\mathrm{FEV}_{1.0} / \mathrm{VC} 63.4$ (38.9-101.3)\%. Median daily use of the ventilator for all patients was 7 hours (range, 6-10 hours).

ABG and laboratory values before and after NPPV are shown in Table 2. The NPPV treatment period was 15 (1124) months. The $\mathrm{pH}$ did not change after NPPV therapy. Overall, $\mathrm{PaO}_{2}$ was significantly higher after NPPV therapy than before NPPV therapy $(P<0.0001)$. In addition, $\mathrm{PaCO}_{2}$ decreased significantly after NPPV therapy $(P=0.0003)$. There were no significant changes in serum creatinine, total protein, albumin, and hemoglobin levels after NPPV therapy.

As shown in Fig. 1, 62\% of patients (18 of 29) showed a decrease in serum UA/Cr after NPPV therapy, but, overall, there was no significant change in serum UA/Cr $(P=0.0688)$. $\Delta \mathrm{UA} / \mathrm{Cr}$ did not correlate with the changes in $\mathrm{PaO}_{2}\left(\Delta \mathrm{O}_{2}\right)$ and $\mathrm{PaCO}_{2}\left(\Delta \mathrm{CO}_{2}\right)$ after NPPV (Fig. 2). Characteristics of the two groups (UA/Cr decrease group and non-UA/Cr decrease group) are shown in Table 3. There were no significant differences in baseline characteristics including age, body mass index (BMI), serum $\mathrm{Cr}$, total protein, albumin, hemoglobin, lung function, and ABG values between the two groups. There was no significant difference in NPPV use such as daily use of the ventilator or the treatment period. Moreover, there was no significant difference in change in BMI, body weight, or any parameter of metabolism. In addition, there was no statistical difference between the two groups in $\Delta \mathrm{O}_{2}$ or $\Delta \mathrm{CO}_{2}$. In the UA/Cr decrease group, 3 of 18 patients suffered CRF exacerbation, whereas in the non-UA/Cr decrease group, 9 of 11 patients suffered CRF exacerbation $(P=0.0021)$. The cumulative proportion of patients who did not suffer exacerbation of CRF in each of the two study groups is shown in Fig. 3. The proportion was significantly higher in the UA/Cr decrease group than in the non-UA/Cr decrease group $(P=0.0003)$. 
DOI: 10.2169/internalmedicine.46.6120

Table 2. Arterial Blood Gas and Laboratory Values before and after NPPV

\begin{tabular}{lccr}
\hline & Before NPPV & After NPPV & $P$ value \\
\hline Arterial blood gas & & & \\
$\mathrm{pH}$ & $7.37(7.31-7.45)$ & $7.38(7.33-7.47)$ & 0.3810 \\
$\mathrm{PaO}_{2}(\mathrm{mmHg})$ & $65.3(39.9-100.2)$ & $76.1(51.9-106.3)$ & $<0.0001$ \\
$\mathrm{PaCO}_{2}(\mathrm{mmHg})$ & $66.2(53.6-102.2)$ & $61.6(46.1-92.5)$ & 0.0003 \\
Laboratory & & & 0.5014 \\
Creatinine $(\mathrm{mg} / \mathrm{dl})$ & $0.6(0.1-.0 .9)$ & $0.6(0.2-1.1)$ & 0.8987 \\
Total protein $(\mathrm{g} / \mathrm{dl})$ & $7.1(5.5-9.0)$ & $7.0(5.8-8.6)$ & 0.9610 \\
Albumin $(\mathrm{g} / \mathrm{dl})$ & $4.1(3.1-4.7)$ & $4.1(2.6-5.0)$ & 0.1275 \\
Hemoglobin $(\mathrm{g} / \mathrm{dl})$ & $12.4(9.6-15.3)$ & $12.3(9.4-15.8)$ & \\
\hline
\end{tabular}

$P$ values obtained by Wilcoxon test.

Data are shown as median values, with ranges in parentheses.

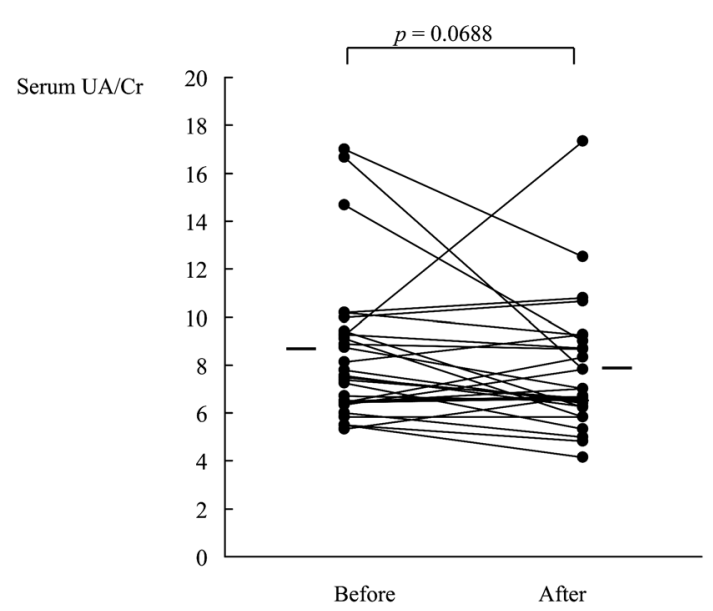

Figure 1. Serum UA levels before and after treatment with NPPV. Serum UA did not change significantly after NPPV therapy $(P=0.0688)$. UA = uric acid; Before = before NPPV therapy; After $=$ after NPPV therapy. $P$ value obtained by Wilcoxin test.

\section{Discussion}

In the present study, long-term NPPV therapy improved hypoventilation. Sixty-two percent of patients (18 of 29) showed a decreased serum UA/Cr, but, overall, there was no significant change in serum UA/Cr after NPPV therapy. There was no significant correlation between $\Delta \mathrm{UA} / \mathrm{Cr}$ and changes in blood gas values. When patients were classified into two groups according to the change in serum $\mathrm{UA} / \mathrm{Cr}$, there were significantly fewer patients who suffered CRF exacerbation in the $\mathrm{UA} / \mathrm{Cr}$ decrease group than in the non$\mathrm{UA} / \mathrm{Cr}$ decrease group. The cumulative proportion of patients who did not suffer CRF exacerbation was significantly higher in the UA/Cr decrease group than in the non-UA/Cr decrease group.
Previous studies have shown that improved oxygenation leads to a decrease in UA (8-12). Basal urinary excretion of adenosine triphosphate catabolic products including UA has been shown to be significantly greater in severely hypoxemic COPD patients than in control patients and to be significantly decreased after oxygen therapy (12). Moreover, in OSAS patients, a significant increase in the UA/Cr has been observed in association with nocturnal hypoxia; nCPAP treatment led to a significant reduction in this ratio (8-11). NPPV therapy, for which compliance was quite excellent, markedly improved the ventilatory state and oxygen supply in our study patients. We hypothesized that long-term NPPV would improve hypoventilation and tissue hypoxia, leading to a decrease in serum UA/Cr. Our results showed that serum UA/Cr tended to decrease after NPPV therapy. However, we failed to show significant correlation between $\Delta \mathrm{UA} / \mathrm{Cr}$ and changes in blood gas values. Previous studies have failed to show a strict relation between $\Delta \mathrm{UA} / \mathrm{Cr}$ and several markers such as the desaturation score, the nadir of arterial oxyhemoglobin desaturation, and daytime blood gas values in patients with OSAS who underwent overnight CPAP therapy $(2,9,11)$. Sato et al showed a negative correlation between the $\triangle \mathrm{UA} / \mathrm{Cr}$ and minimum $\mathrm{SpO}_{2}$ in $\mathrm{COPD}$ patients receiving LTOT. Why did we fail to find a correlation between $\Delta \mathrm{UA} / \mathrm{Cr}$ and $\Delta \mathrm{O}_{2}$ ? The possible explanations are as follows: the level of hypoxemia alone may not predict the presence of tissue hypoxia. Tissue hypoxia indicates inadequate oxygen supply against oxygen demand in the integrity of cellular metabolic processes (29). Oxygen delivery to the periphery is determined by two major factors: oxygen content of arterial blood, which is calculated by the hemoglobin concentration, $\mathrm{SaO}_{2}$, and $\mathrm{PaO}_{2}$, and the amount of blood flow, i.e., cardiac output (29). Other factors such as the oxyhemoglobin dissociation curve and $\mathrm{pH}$ also influence oxygen delivery. Thus, levels of $\mathrm{PaO}_{2}$ correlate poorly with tissue hypoxia (9). In addition, improvement of pulmonary hypertension leads to a decrease in serum UA. Serum UA levels decreased in association with a reduction in total pul- 


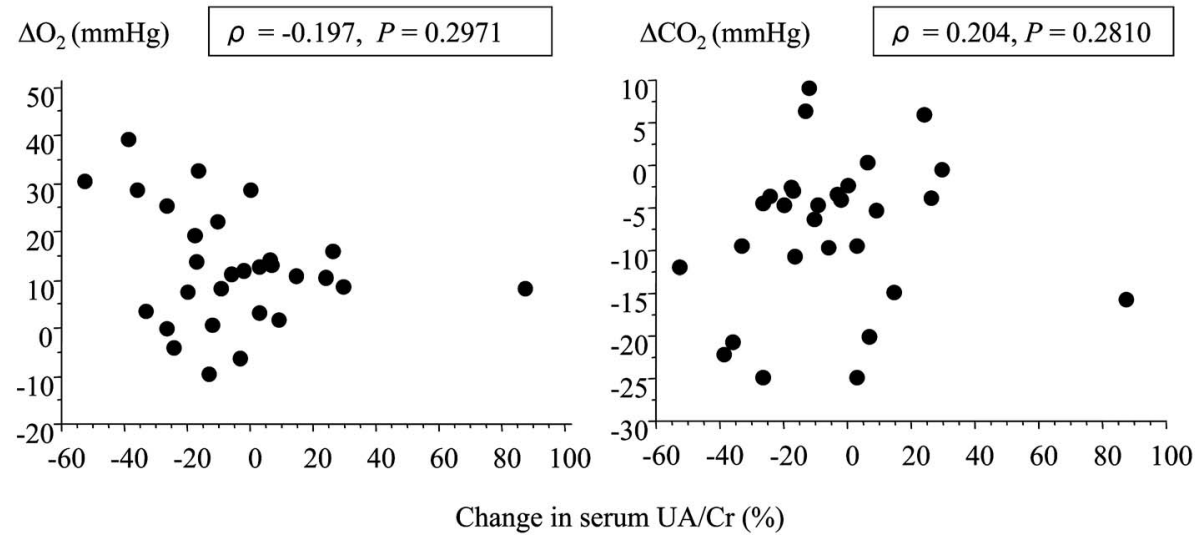

Figure 2. Correlation between $\triangle \mathrm{UA}$ and changes in blood gas values. $\Delta \mathrm{UA}=100 \% \times($ serum UA after NPPV therapy- serum UA before NPPV therapy)/ serum UA before NPPV therapy; $\Delta \mathrm{O}_{2}=$ $\mathrm{PaO}_{2}$ after NPPV therapy $-\mathrm{PaO}_{2}$ before NPPV therapy; $\Delta \mathrm{CO}_{2}=\mathrm{PaCO}_{2}$ after NPPV therapy $-\mathrm{PaCO}_{2}$ before NPPV therapy. $P$ value obtained by Spearman's rank correlation coefficient.

Table 3. Baseline Characteristics, ABG Changes, and Number of Patients who Suffered CRF Exacerbation in the Two Study Groups

\begin{tabular}{|c|c|c|c|}
\hline & UA/Cr decrease $(n=18)$ & non-UA/Cr decrease $(\mathrm{n}=11)$ & $P$ value \\
\hline \multicolumn{4}{|l|}{ Baseline characteristics } \\
\hline Age (years) & $70(58-80)$ & $71(54-81)$ & 0.8573 \\
\hline $\mathrm{BMI}\left(\mathrm{kg} \cdot \mathrm{m}^{-2}\right)$ & $18.1(14.2-28.2)$ & $15.6(13.6-30.2)$ & 0.9641 \\
\hline \multicolumn{4}{|l|}{ Diuretics/ no diuretics } \\
\hline (no. of patients) & $9 / 9$ & $7 / 4$ & $0.7301 *$ \\
\hline Creatinine (mg/dl) & $0.6(0.1-0.9)$ & $0.6(0.4-0.9)$ & 0.1635 \\
\hline Total protein $(\mathrm{g} / \mathrm{dl})$ & $7.1(5.5-9.0)$ & $6.9(5.9-7.4)$ & 0.2112 \\
\hline Albumin (g/dl) & $4.1(3.1-4.7)$ & $4.1(3.6-4.3)$ & 0.4539 \\
\hline Hemoglobin $(\mathrm{g} / \mathrm{dl})$ & $12.9(10.6-15.3)$ & $12.4(9.6-13.8)$ & 0.2484 \\
\hline $\mathrm{VC}(\mathrm{L})$ & $0.97(0.47-2.06)$ & $1.16(0.68-2.11)$ & 0.0532 \\
\hline$\% \mathrm{VC}(\%)$ & $35.0(21.6-56.0)$ & $42.1(25.4-58.6)$ & 0.1514 \\
\hline $\mathrm{FEV}_{1.0}(\mathrm{~L})$ & $0.55(0.34-1.13)$ & $0.82(0.36-1.04)$ & 0.2487 \\
\hline $\mathrm{pH}$ & $7.37(7.33-7.45)$ & $7.37(7.30-7.43)$ & 0.9641 \\
\hline $\mathrm{PaO}_{2}(\mathrm{mmHg})$ & $64.0(39.9-100.2)$ & $70.0(46.2-81.9)$ & 0.8573 \\
\hline $\mathrm{PaCO}_{2}(\mathrm{mmHg})$ & $64.4(55.4-102.2)$ & $69.2(53.6-101.1)$ & 0.6531 \\
\hline \multicolumn{4}{|l|}{ ABG changes } \\
\hline$\Delta \mathrm{O}_{2}(\mathrm{mmHg})$ & $11.8(-9.4-39.3)$ & $10.9(1.7-29.0)$ & $>0.9999$ \\
\hline$\Delta \mathrm{CO}_{2}(\mathrm{mmHg})$ & $-4.5(-24.7--1.2)$ & $-5.3(-24.8-6.1)$ & $>0.9999$ \\
\hline Treatment period (months) & $15(12-24)$ & $16(11-23)$ & 0.8220 \\
\hline Daily ventilator use (hours) & $7(6-10)$ & $7(6-9)$ & 0.2644 \\
\hline \multicolumn{4}{|l|}{ Exacerbation/No exacerbation } \\
\hline (no. of patients) & $3 / 15$ & $9 / 2$ & $0.0021^{*}$ \\
\hline $\begin{array}{l}\mathrm{ABG}=\text { arterial blood gas analysi } \\
\text { volume in } 1 \text { second, } \Delta \mathrm{O}_{2}=\mathrm{PaO}_{2} \\
-\mathrm{PaCO}_{2} \text { before NPPV therapy. }\end{array}$ & $\begin{array}{l}\text { s, } \mathrm{CRF}=\text { chronic respirato } \\
\text { after NPPV therapy- } \mathrm{PaO}_{2}\end{array}$ & $\begin{array}{l}\text { ailure, } \mathrm{VC}=\text { vital capacity, } \mathrm{FEV} \\
\text { re NPPV therapy, } \Delta \mathrm{CO}_{2}=\mathrm{PaCC}\end{array}$ & $\begin{array}{l}=\text { forced expiratory } \\
\text { after NPPV therapy }\end{array}$ \\
\hline \multicolumn{4}{|c|}{$\begin{array}{l}P \text { values obtained by Mann-Whitney } U \text { test no less than otherwise indicated. Data are shown as median values, with } \\
\text { ranges in parenthesis. }\end{array}$} \\
\hline
\end{tabular}




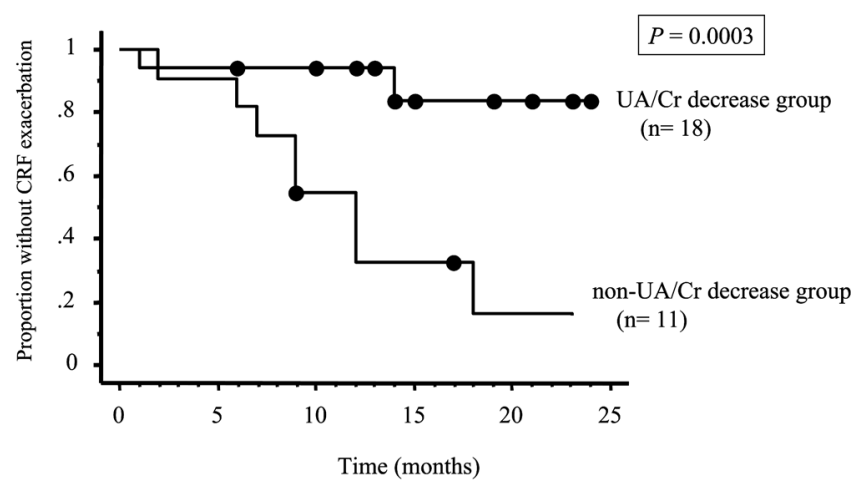

Figure 3. Kaplan-Meier plot showing the proportion of patients without exacerbation of CRF in each of the two study groups. The UA decrease group had a significantly higher proportion of patients who did not suffer exacerbation of CRF than the non-UA decrease group had $(P=0.0003$ by $\log$ rank test). $\mathrm{CRF}=$ chronic respiratory failure.

monary resistance during vasodilator therapy in patients with primary pulmonary hypertension (16). In patients with RTD, long-term NPPV therapy reportedly improved pulmonary hemodynamics $(30,31)$. Lack of improvement in pulmonary hypertension may lead to lack of a decrease in UA in some patients. Finally, lack of a significant relation between $\Delta \mathrm{UA} /$ $\mathrm{Cr}$ and $\Delta \mathrm{O}_{2}$ might have been due simply to the small sample group.

Serum UA may be a useful clinical marker for exacerbation of CRF in patients with RTD. Previous studies have shown that serum UA increases in proportion to the severity of heart failure $(15,16)$ and that it is a strong prognostic marker in patients with chronic heart failure $(14,15)$, pri- mary pulmonary hypertension (16), and Eisenmenger syndrome (18). Concerning CRF, Sato et al reported that $\triangle \mathrm{UA} /$ $\mathrm{Cr}$ is a reliable indicator of prognosis in COPD patients receiving LTOT (13). However, there has been no report of the clinical significance of serum UA/Cr in RTD patients. In the present study, significantly fewer RTD patients who showed a decrease in serum UA/Cr (versus those who did not show a decrease) suffered CRF exacerbation. Furthermore, the cumulative proportion of patients without exacerbation of CRF was significantly higher in the UA/Cr decrease group than in the non-UA/Cr decrease group. Thus, our data suggest that $\mathrm{UA} / \mathrm{Cr}$ is a valuable predictor of $\mathrm{CRF}$ exacerbation in RTD patients treated by NPPV. Why did such patients not show a decrease in serum UA/Cr despite the improved oxygenation? As noted above, the difference in the extent of improvement in pulmonary hemodynamics, $\mathrm{SaO}_{2}$, the oxyhemoglobin dissociation curve, and $\mathrm{pH}$ may have influenced on the proportion of patients with CRF exacerbation in the two groups.

Mention should be made of the study limitations. First, diuretics, theophylline, digitalis, and aspirin are known to affect serum UA metabolism $(2,9)$. In this study, $52 \%$ of patients (15 of 29) were taking loop diuretics, and $24 \%$ of patients (7 of 29) were taking theophylline. Thus, we did not change any medical treatment, such as diuretics and theophylline, and we compared laboratory data including ABG values before and after NPPV therapy. Second, the treatment period varied from 11 to 24 months. However, there was no significant difference in the treatment period between the UA decrease group and the non-UA decrease group. Further study in a large number of patients may confirm the usefulness of this simple, inexpensive test for periodic follow-up of patients with CRF receiving NPPV.

\section{References}

1. Krachman SL, Criner GJ. Sleep and long-term ventilation. Respir Care Clin N Am 8: 611-629, 2002.

2. Hasday JD, Grum CM. Nocturnal increase of urinary uric acid: creatinine ratio. A biochemical correlate of sleep-associated hypoxemia. Am Rev Respir Dis 135: 534-538, 1987.

3. Yoshino M, Hayashi R, Katsumata Y, Mori S, Mitarai G. Blood oxypurines and erythrocyte 2, 3-diphosphoglycerate levels at high altitude hypoxia. Life Sci 27: 1265-1269, 1980.

4. Kintner D, Costello DJ, Levin AB, Gilboe DD. Brain metabolism after 30 minutes of hypoxic or anoxic perfusion or ischemia. Am J Physiol 239: E501-509, 1980.

5. Saugstad OD, Aasen AO, Hetland O. Plasma hypoxanthine levels in pigs during acute hypoxemia. A correlation between lactate and base deficit concentrations. Eur Surg Res 10: 314-321, 1978.

6. Sutton JR, Toews CJ, Ward GR, Fox IH. Purine metabolism during strenuous muscular exercise in man. Metabolism 29: 254-260, 1980.

7. Grum CM, Simon RH, Dantzker DR, Fox IH. Evidence for adenosine triphosphate degradation in critically-ill patients. Chest 88: 763-767, 1985.

8. Saito H, Nishimura M, Shibuya E, et al. Tissue hypoxia in sleep apnea syndrome assessed by uric acid and adenosine. Chest 122: 1686-1694, 2002.
9. Braghiroli A, Sacco C, Erbetta M, Ruga V, Donner CF. Overnight urinary uric acid: creatinine ratio for detection of sleep hypoxemia. Validation study in chronic obstructive pulmonary disease and obstructive sleep apnea before and after treatment with nasal continuous positive airway pressure. Am Rev Respir Dis 148: 173-178, 1993.

10. Mckeon JL, Saunders NA, Murree-Allen K, et al. Urinary uric acid: creatinine ratio, serum erythropoietin, and blood 2, 3diphosphoglycerate in patients with obstructive sleep apnea. Am Rev Respir Dis 142: 8-13, 1990.

11. Sahebjami H. Changes in urinary uric acid excretion in obstructive sleep apnea before and after therapy with nasal continuous positive airway pressure. Chest 113: 1604-1608, 1998.

12. Mateos FA, Gomez PF, Puig JG, Jimenez ML, Ramos TH, Mantilla JG. Enhanced adenine nucleotide degradation in chronic obstructive pulmonary disease: the effect of oxygen therapy. Adv Exp Med Biol 253A: 333-338, 1989.

13. Sato N, Kurashima K, Ubukata M, et al. Prognostic significance of serum uric acid in patients with chronic obstructive pulmonary disease receiving home oxygen therapy. Nihon Kokyuki Gakkai Zasshi 41: 74-80, 2003 (in Japanese, Abstract in English).

14. Anker SD, Doehner W, Rauchhaus M, et al. Uric acid and survival in chronic heart failure: validation and application in meta- 
bolic, functional, and hemodynamic staging. Circulation 107: 1991-1997, 2003.

15. Leyva F, Anker S, Swan JW, et al. Serum uric acid as an index of impaired oxidative metabolism in chronic heart failure. Eur Heart J 18: 858-865, 1997.

16. Nagaya N, Uematsu M, Satoh T, et al. Serum uric acid levels correlate with the severity and the mortaliry of primary pulmonary hypertension. Am J Respir Crit Care Med 160: 487-492, 1999.

17. Hayabuchi Y, Matsuoka S, Akita H, Kuroda Y. Hyperuricaemia in cyanotic congenital heart disease. Eur J Pediatr 152: 872-876, 1993.

18. Oya $H$, Nagaya $N$, Satoh $T$, et al. Haemodynamic correlates and prognostic significance of serum uric acid in adult patients with Eisenmenger syndrome. Heart 84: 53-58, 2000.

19. Mehta S, Hill NS. Noninvasive ventilation. Am J Respir Crit Care Med 163: 540-577, 2001.

20. Buyse B, Meersseman W, Demedts M. Treatment of chronic respiratory failure in kyphoscoliosis: oxygen or ventilation? Eur Respir J 22: 525-528, 2003.

21. Fishman AP, Elias JA, Fishman JA, Grippi MA, Kaiser LR, Senior RM. Respiratory failure: an overview. In: Fishman's Pulmonary Disease and Disorders. 3rd ed., Vol. 2. Fishman AP, Elias JA, Fishman JA, Grippi MA, Kaiser LR, Senior RM, Eds. McGrawHill, New York, 1997.

22. Bach JR. Noninvasive Mechanical Ventilation. Hanley \& Belfus, Philadelphia, 2002.

23. Masa JF, Celli BR, Riesco JA, Sanchez de, Cos J, Disdier C, Sojo A. Noninvasive positive pressure ventilation and not oxygen may prevent overt ventilatory failure in patients with chest wall diseases. Chest 112: 207-213, 1997.
24. Domagk GF, Schlicke HH. A colorimetric method using uricase and peroxidase for the determination of uric acid. Anal Biochem 22: 219-224, 1968

25. Langlois M, De Bacquer D, Duprez D, De Buyzere M, Delanghe J, Blaton V. Serum uric acid in hypertensive patients with and without peripheral arterial disease. Atheroscrelosis 168: 163-168, 2003.

26. ATS/ERS COPD Guidelines, http://www.ersnet.org/lrPresentations/ copd/files/main/index.html.

27. Todisco T, Baglioni S, Eslani A, et al. Treatment of acute exacerbations of chronic respiratory failure: integrated use of negative pressure ventilation and noninvasive positive pressure ventilation. Chest 125: 2217-2223, 2004.

28. Fletcher CM. The clinical diagnosis of pulmonary emphysema; an experimental study. Proc R Soc Med 45: 577-584, 1952.

29. Beers MF. Oxygen therapy and pulmonary oxygen toxicity. Fishman's Pulmonary Diseases and Disorders. 3rd ed., Fishman AP, Elias JA, Fishman JA, Grippi MA, Kaiser LR, Senior RM, Eds. Vol. 2. McGraw-Hill, New York, 1997.

30. Schohofer B, Barchfeld T, Wenzel M, Kohler D. Long term effects of non-invasive mechanical ventilation on pulmonary haemodynamics in patients with chronic respiratory failure. Thorax 56: 524-528, 2001.

31. Kadowaki T, Hamada H, Hamaguchi N, et al. Successful treatment of secondary pulmonary hypertension by long-term noninvasive positive pressure ventilation. Respir Med Extra 2007 (in press).

(C) 2007 The Japanese Society of Internal Medicine http://www.naika.or.jp/imindex.html 